\title{
BREEAM Communities in Spain
}

\author{
A. L. Cabrita \& J. R. Alvarez \\ BREEAM España, Instituto Tecnológico de Galicia, Spain
}

\begin{abstract}
Environmental assessment methods are widely recognised as one of the most efficient strategies to encourage environmental responsibility in the building sector. This recognition is based on more than 20 years of implementation, during which these methods have been adopted by the industry and stakeholders and have stimulated a demand for sustainable construction. BREEAM is the world's leading environmental certificate with over 201,000 certified buildings. The methodology on which it is based has benefited from the broad experience of the Building Research Establishment and its many years of research. A new BREEAM scheme has been recently launched to address the impact of development projects within the built environment. BREEAM Communities identifies a holistic set of indicators and performance targets that will eventually determine the robustness of the urban project. The selection of targets and benchmarks and the definition of the assessment framework are key issues that are strongly determined by the geographic and social context. The ITG (Instituto Tecnológico de Galicia) is now responsible for the adaptation and future implementation of BREEAM Communities into the Spanish context. The adaptation process will involve extensive consultation with a broad range of experts and stakeholders that will provide feedback in some 40 areas of expertise, thus generating a comprehensive knowledge base about sustainable urbanization. This paper will point out the main issues that are to be considered during this process and how the assessing criteria will interact with the Spanish legal and environmental framework.
\end{abstract}

Keywords: environmental assessment, labelling, certificate, sustainable communities, BREEAM, ITG. 


\section{Introduction}

Modern society has reached maturity and is now aware that a different dialogue with the environment is needed. The turning point at the Industrial Revolution gave rise to the first measures to mitigate the impact of human activities and to improve health conditions. That was the origin of the modern planning, which intended to control the way the city should grow. However, soon after, environmental concern in town planning fell into abeyance to give ground to other social or economic considerations. Once that wellbeing had been achieved, in the last quarter of the century the view went back again to examining the use of natural resources and the impact of development on Earth. As a result, contemporary society demands more information and objective quantification of the impact of their activities.

Environmental impact assessment has become a key environmental mechanism in the last 30 years. The National Environmental Protection Act (NEPA, 1969) in the United States and Directive 85/377, amended by Council Directive 97/11/EC in Europe, required proper assessment when planning decisions were likely to have an impact on the environment [1]. The information about this potential impact is gathered by developers and supplied to decision makers. EIAs are being currently applied in different ways and to different levels depending on the regional context; this diversity makes comparison and extrapolation difficult and consequently, it limits the purposive potential of these tools.

The Building Research Establishment Environmental Assessment Method (BREEAM) has narrowed the gap among developers, professionals and decision makers by setting a transparent framework that enhances synergies of the planning application process with specific sustainable targets. It does not replace any existing legislation and it is not compulsory, but both planning authorities and developers can directly benefit from it; the former by the assistance for decision making and the latter by improving the efficiency of the application process while demonstrating the sustainability of the project. The potential of this approach is verified by more than 200,000 evaluated and 700,000 registered buildings around the globe. It is expected that BREEAM Communities will help to identify and promote good practise at the urban scale in Spain too.

In recent years, the Institute of Technology of Galicia, which has a strong connection to professional practise and the building industry, had detected a gap in the environmental appraisal of buildings and development projects in Spain. Current legislation does normally address a very late stage in the design process, which makes innovation very difficult. On the other hand, the town planning system varies for each region and so does environmental legislation. As a result, comparison and extrapolation becomes fruitless as the outcomes are strongly determined by the legal framework. In this context, the need for a tool which truly addresses sustainable design from the very early stage, facilitating clear and objective performance targets became crucial. The solid background of 
BREEAM Communities and its flexibility to adapt to the heterogeneous Spanish context made it a suitable candidate.

\section{Sustainable communities}

When the Brundtland Commission first defined the concept of Sustainable Development as "development that meets the needs of the present without compromising the ability of future generations to meet their own needs" [2] it was suggesting a double compromise; firstly, the idea of meeting the needs of the present implies a concept of satisfaction thus stability of the recently achieved social welfare. On the other hand, it suggests that an account of available resources and depletion rates are needed; in other words, an objective evaluation to ensure that the cyclic process can be sustained over time. More recently, the Communities and Local Government had defined a Sustainable Community as places where "people want to live and work, now and in the future, meeting the diverse needs of existing and future resident" [3]. Securing wellbeing over time is a key aspect, which necessarily leads to a holistic approach where social, economic and environmental issues are to be considered. This global definition could be applicable to any developed region and it is therefore a common ground from which each local community could define a specific response.

To be effective, the local response should be:

- Aware about the local context; strengths, weaknesses, opportunities and threats from social, economic and environmental perspectives

- Clear and consistent; to establish priorities, sustainable objectives which are feasible and measurable

- Scientific rather than speculative, i.e. well informed about the state of the art in sustainable development research

- Constructive; focusing on synergies rather than on obstacles

- Compatible with the social and legal context

- Far-sighted, to foresee how to monitor the achievement of sustainable targets

- Flexible and adaptable; as priorities may evolve with time

This sequential approach starts with a global objective, sustained wellbeing, which is tested by the achievement of specific targets. In a good logic, these targets are strongly influenced by the context. The importance of different parameters depends on location, background, nature and character of the site. However, the methods to establish, monitor and assess those indicators, can greatly benefit from certain levels of standardization, so that the robustness of the method can be verified under different realities. These methods should also observe and be observed by national legislation so as to avoid digressions or contradictions.

The UK government, for instance, had launched a global agenda for sustainable communities whose main objectives have been included in the different BREEAM categories, whereas in Spain, national urban regulations are 
rather sectoral. In the Spanish case, the sustainable character of a development is based on its impact upon nature and landscape conservation, social or economic issues are rather neglected or diverted to other sectoral laws. The elaboration of a sustainable framework by BREEAM Communities will facilitate the work of designers and their communication with decision makers.

\section{BREEAM Communities and environmental impact assessment}

Although BREEAM Communities is not an environmental impact assessment method, these were immediate and close precedents. There are certain similarities as well as notable differences in the objectives and procedural techniques from both.

After EIA directive, provision of information about the effect on the environment of certain activities has to be compiled before any final decision is taken. The specific definition of those activities was left for each state member. In UK, planning applications are divided in Schedule 1, for which EIA is compulsory (e.g. chemical plants, thermal and nuclear power stations...) and schedule 2, in which case the relevant planning authority decides whether it is necessary or not according to an screening process [4]. In Spain, the national law [5] listed a series of activities (agricultural, industrial, infrastructures...) for which EIA is statutory; planning is not explicitly mentioned at this level as it is a privilege of regional assemblies to establish the specific conditions for town and country planning on their territory. Normally, council development plans need to undertake an EIA and this evaluation satisfies every inferior development within the municipality that is not included in the national list of activities. It means that a masterplan for a new neighbourhood might not require an EIA.

BREEAM Communities does not replace any existing legislation, and therefore it is not a substitute for EIA. However, it is a tool that can assist decision makers by providing objective information and support in a number of areas concerning urban sustainability. It is a third party voluntary assessment certification standard that enables to demonstrate and verify the environmental performance of urban developments. BREEAM implements national, regional and local planning policy requirements to create a common framework, facilitating the application process. Moreover, developers can benefit from an improved image and added value in the marketplace. This will encourage the adoption of standards beyond regulations to achieve a higher level and consequently a higher score in the certificate.

The contents of an EIA can vary depending of its nature, for this reason there is a scoping process, to determine the coverage of the environmental impact assessment and the specific issues to be addressed. The scoping is requested from developers to the planning authorities and although is not mandatory it is strongly recommended [4]. Developers can identify the issues to be analyzed by using a systematic method (checklist, flowcharts...) before scoping is undertaken by planning authorities. Some common categories are typically addressed by EIA: 
- Socio economic impact. The key indicator is usually the increase of population, direct or indirect

- Noise impact prediction, during and after the work

- Transport, prediction of trip attraction of the site, trip distribution and modes of transport

- Air quality and climate impact, predicted emission rates, comparison with air quality standards

- Soils, geology and geomorphology. Information of contaminated land and remediation, impact prediction on soil (erosion, pollution...)

A sustainable development framework combines statutory planning requirements with specific environmental, social and economic sustainability objectives. Compliant assessment methodologies assist in the elaboration of specific targets to be met on a future development (for instance Regional Sustainability Checklists). BREEAM Communities has defined, structured and weighted the issues and categories which are recurrent in sustainable developments to create a comprehensive assessment framework. It covers the following categories:

- Climate and energy

- Community

- Place shaping

- Transport

- Resources

- Ecology

- Business

- Buildings.

Finally, the EIA intends to illustrate or predict the effects on an activity that, by definition, is likely to have an important impact. As a result, they are often used as defensive tools to demonstrate that the benefits (normally economic) from that activity can justify the expected impact on the environment. It is information compiled by developer for decision makers to judge the balance between the benefits and drawbacks and based on that, they grant permission. For this reason, it is normally oriented to enhance the benefits of the project. On the other hand, the amount and complexity often goes beyond the possibilities of local planning authorities which do not have the level of expertise of specialized consulting bureaus. This can compromise the actual effectiveness or veracity of the assessment.

BREEAM is an independent certification for residential, mixed-use and nondomestic developments. Since it is voluntary, developers have to set their sustainability targets from the outset. These targets can be agreed with the local authority and be based on the framework which is given by BREEAM Communities, which makes communication easier. Once these targets are clear, the design team can orientate the projects towards the achievement of those goals. This sequence will allow the integration between sustainability objectives and the design process, therefore making a real effect in the quality and impact of future developments. 


\section{Methodology of BREEAM Communities in the UK}

The BREEAM Communities scheme has been specifically designed to assess the environmental impact of developments within the English Regions. It has been tailored to the specific planning policy requirements of England. Therefore, for any other region or state, an adaptation of the schemes will be needed. However, the essence of the essence, structure, process and methodology will remain invariable.

\subsection{The process}

The process to get a BREEAM Communities certification has three main stages. It starts with the registration of a compliant assessment framework; this is a mandatory requirement if a development wants to achieve certification against the BREEAM Communities standard. The compliant assessment framework provides the foundation from which specific sustainability objectives and relevant planning requirements are established. It can be agreed between the development team and the planning authority. BREEAM Communities defines the core criteria which should be used to form the base of the compliant assessment framework that a BREEAM Communities assessor will finally compile and report on.

The second stage is an optional Interim Certificate at the Outline Planning Stage. It measures the level of achievement of the targets outlined at the preliminary planning stage against the key sustainability objectives and planning policies. It does not contain a final assessment rating but indicates whether the submitted assessment report has passed or failed. Therefore, it cannot be used to replace the "final" certificate, as there is not enough detail at this stage. It is very effective to consider environmental, social and economic sustainability issues from the outset as this will assist in achieving higher level objectives optimizing resources and cost.

At the third stage, the Detailed Planning Stage, a "Final" Certification measures the detailed commitments outlined within the final planning stage application against the key sustainability objectives and planning policy requirements. The final certificate can be achieved by either completing a review of the Outline Planning Stage or by proceeding directly to the detailed planning application assessment [6].

\subsection{Environmental indicators}

The BREEAM Communities scheme addresses social, economic and environmental sustainability by defining a performance targets and assessment criteria that must be met to confirm the target has been achieved. Credits are awarded based on the masterplan's performance against those criteria. Table 1 explains the eight categories and the respective environmental issues that are covered: 
Table 1: $\quad$ Summary of BREEAM Communities' categories [7].

\begin{tabular}{|c|c|c|}
\hline \multicolumn{2}{|c|}{ Category Description } & \multirow{2}{*}{$\begin{array}{l}\text { Issues Covered } \\
\text { - Flood Management } \\
\text { - Energy and Water Efficiency } \\
\text { - Renewable Energy } \\
\text { - Infrastructure } \\
\text { - Passive Design Principles }\end{array}$} \\
\hline $\begin{array}{l}\text { Climate and } \\
\text { Energy }\end{array}$ & $\begin{array}{l}\text { Reducing the proposed project's } \\
\text { contribution to climate change whilst } \\
\text { ensuring that developments are } \\
\text { appropriately adapted to the impacts } \\
\text { of present and future climate change. }\end{array}$ & \\
\hline Resources & $\begin{array}{l}\text { Designing for the efficient use of } \\
\text { resources including water, materials } \\
\text { and waste in construction, operation } \\
\text { and demolition, and minimising the } \\
\text { life cycle impacts of materials chosen. }\end{array}$ & $\begin{array}{l}\text { - Land Use and Remediation } \\
\text { - Material Selection } \\
\text { - Waste Management } \\
\text { - Construction Management } \\
\text { - Modern Methods of Construction }\end{array}$ \\
\hline Transport & $\begin{array}{l}\text { Addressing how people can get to } \\
\text { the facilities and locations that they } \\
\text { need; giving people choices other } \\
\text { than private cars and encouraging } \\
\text { walking and cycling for healthier } \\
\text { lifestyles. }\end{array}$ & $\begin{array}{l}\text { - Walkable Neighbourhoods } \\
\text { - Cycle Networks } \\
\text { - Provision of Public Transport } \\
\text { - Green Travel Plans } \\
\text { - Construction Transport }\end{array}$ \\
\hline Ecology & $\begin{array}{l}\text { Conserving the ecology living on and } \\
\text { visiting the site and taking full } \\
\text { opportunity for ecological } \\
\text { enhancement within and around the } \\
\text { development as well as on buildings. }\end{array}$ & $\begin{array}{l}\text { - Maintaining / Enhancing Habitat } \\
\text { - Green Corridors } \\
\text { - Ground Pollution } \\
\text { - Contaminated Land } \\
\text { - Landscaping Schemes } \\
\end{array}$ \\
\hline Business & $\begin{array}{l}\text { Providing opportunities for } \\
\text { businesses to locate and serve both } \\
\text { the locality and provide jobs for } \\
\text { people living in and around the } \\
\text { development. }\end{array}$ & $\begin{array}{l}\text { - Inward Investment } \\
\text { - Local Employment } \\
\text { - Knowledge Sharing } \\
\text { - Sustainable Charters }\end{array}$ \\
\hline Community & $\begin{array}{l}\text { Designing the development to } \\
\text { support a vibrant new community } \\
\text { which can integrate with surrounding } \\
\text { areas, avoiding creating actual or } \\
\text { perceived "gated" communities. }\end{array}$ & $\begin{array}{l}\text { - Social Impact Assessment } \\
\text { - } \text { Community Engagement } \\
\text { - Sustainable Lifestyles } \\
\text { - Facilities Management } \\
\text { - Mixed of Use } \\
\text { - Affordable Housing }\end{array}$ \\
\hline Place Shaping & $\begin{array}{l}\text { Provide a framework for the design } \\
\text { of a 'real place' with an identity that } \\
\text { ensures that people can instinctively } \\
\text { find their way around. Also ensuring } \\
\text { that the new development draws } \\
\text { from the local context and heritage. }\end{array}$ & $\begin{array}{l}\text { - Site Selection } \\
\text { - } \text { Defensible Space } \\
\text { - Active Frontages } \\
\text { - Sreen Space } \\
\text { - Hocured by Design } \\
\text { - Housing Density }\end{array}$ \\
\hline Buildings & \begin{tabular}{|l|} 
Ensuring that the design of \\
individual buildings contribute to the \\
sustainability of the overall \\
development through high \\
environmental standards.
\end{tabular} & $\begin{array}{l}\text { - BREEAM Buildings } \\
\text { - Code for Sustainable Homes } \\
\text { - EcoHomes }\end{array}$ \\
\hline
\end{tabular}




\subsection{Rating and certification}

Certification of the compliant assessment framework against the BREEAM Communities standard is undertaken by an independent and qualified BREEAM assessor. He verifies that the commitments have been followed through by the development team by collecting the evidence. He compiles an assessment report which is submitted to BRE Global for quality assurance and certification.

The final score is determined by a sequence of filters and weightings:

- Rating benchmarks

- Regional weightings

- Mandatory or optional credit issues

- Credits for innovation

\subsubsection{Rating benchmarks}

The rating benchmarks are spread out in short intervals as an incentive to encourage improvements from development teams. They are expressed as a percentage of the available credits for each region and type:

- Unclassified $<25 \%$

- Pass $\geq 25 \%$

- Good $\geq 40 \%$

- Very Good $\geq 55 \%$

- Excellent $\geq 70 \%$

- Outstanding* $\quad \geq 85 \% *$ It requires additional requirements

\subsubsection{Regional weightings}

A regional weighting factor has been determined by expert groups to provide the necessary regional variation between specific issues according to their importance on that specific context. These weighting will be applied to the credits achieved for that issue. For instance, according to the factors illustrated in table 2, the water strategy of the masterplan (RES5) can award one, two or three credits (as usual) if it fulfils the requisites for each level. However, due to the regional weightings, if the development is located in the North West Region, these credits are reduced to $0.5,1$ and 1.5 respectively, as result of applying the 0.5 factor.

Table 2: $\quad$ Example of regional weightings.

\begin{tabular}{|l|c|c|c|c|c|c|c|c|c|c|}
\hline & London & $\begin{array}{c}\text { South } \\
\text { East }\end{array}$ & $\begin{array}{c}\text { South } \\
\text { West }\end{array}$ & $\begin{array}{c}\text { North } \\
\text { East }\end{array}$ & $\begin{array}{c}\text { North } \\
\text { West }\end{array}$ & $\begin{array}{c}\text { East } \\
\text { Mids }\end{array}$ & $\begin{array}{c}\text { West } \\
\text { Mids }\end{array}$ & $\begin{array}{c}\text { East } \\
\text { England }\end{array}$ & Yorkshire \\
\hline RES5 & $\begin{array}{c}\text { Water } \\
\text { Resources - } \\
\text { Masterplanning } \\
\text { Strategy }\end{array}$ & 1,0 & 1,0 & N/A & 0,9 & 0,5 & 1,0 & 1,0 & 1,0 & 1,0 \\
\hline RES6 & $\begin{array}{c}\text { Water } \\
\text { Resources - } \\
\text { Groundwater }\end{array}$ & 1,0 & 1,0 & 1,0 & 1,0 & 0,8 & 1,0 & 1,0 & 1,0 & 1,0 \\
\hline
\end{tabular}




\subsubsection{Mandatory and optional credits}

Each BREEAM issue establishes performance targets that fulfil and go beyond the minimum standard to satisfy planning policy requirements or other legislation. The targets represent minimum, good or best practice in sustainable development. Some issues are deemed mandatory by national policies, when this is the case, it is named as a core issue and the minimum standard requirement has to be fulfilled to achieve a BREEAM certificate. There are, therefore, a number of core credits that have to be necessarily achieved to pass the assessment. The optional credits are credits which are available to improve the final scoring, There is a maximum of three credits for each issue; the first one represents the minimum, which can be compulsory or not, the second credit is awarded when good practice is demonstrated by some specific evidences, the third credit is awarded when the masterplan satisfies the equivalent to best practice. Some of the optional credits become compulsory when the development aspires to "Outstanding" rating. It means that "Outstanding" certification cannot be achieved without those credits.

\subsubsection{Credits for innovation}

Innovation credits provide additional recognition of a development that innovates in the field of sustainable performance. An additional 1\% score can be added to a community project's final BREEAM score for each Innovation credit achieved up to a maximum of $10 \%$. The achievement of an Innovation credit follows a specific process that includes written approval from the BREEAM Office.

\subsubsection{Score rating and calculation}

The process of calculation a BREEAM Communities rating is done by a BREEAM assessor and it is as follows:

- First, the assessor determines the number of credits awarded for each issue, according to the established requirements.

- Secondly, those credits are multiplied by the regional weightings to provide the score available for each issue.

- The section scores are added together to give the overall score which is then compared to the benchmarks. Provided that all core requirements have been met, the relevant rating is achieved.

- Finally, innovation credits can be added.

\section{BREEAM Communities adaptation to Spain}

The Institute of Technology of Galicia (ITG) is non-profitable private Foundation which was founded in 1991 by the Official Chambers of Architects, Civil Engineers and Industrial Engineers. The ITG is working in collaboration with BRE Global in the development and adaptation to the Spanish context of a number of BREEAM schemes. BREEAM Communities is now on an advance stage on that adaptation process and the Spanish version is expected to be released by early 2011 . 


\subsection{Benefits of BREEAM Communities in Spain}

The implementation of a sustainable development assessment tool is relevant and of absolute necessity in the Spanish context. For many decades, environmentally conscious architecture had been a marginal field. Professionals with a focus on sustainable design were scarce and underestimated. However, in recent years, bioclimatic attributes have started to be seen as an added value in the market place and consequently, claims about good environmental performance and the sustainable character of buildings sprung up everywhere. That led to the definition of "greenwashing" as those unsupported allegations about the low environmental impact of a product. In Spain, this lack of rigour has been partially solved with the compulsory display of energy certificates, although it only covers part of the building's environmental performance (as it is regardless of water, impact on other buildings, etc...) In urban planning the situation is even more dramatic and the eco-ism has proliferated at every scale (eco-towns, eco-neighbourhoods, etc.) In many cases these claims are not supported by transparent and clear arguments and the actual performance cannot be compared or tested against benchmarks. A primarily benefit of BREEAM Communities will be to provide an objective tool to demonstrate the sustainability of urban developments. Therefore, a verifiable good environmental performance will be encouraged over mere cosmetics or superficial greenwashing.

\subsubsection{Benefits for developers and project teams}

BREEAM Communities will allow to effectively demonstrate the sustainability of the masterplan to the local authority, market place and industry in general. It will also allow standardizing the approach to planning requirements so as to improve efficiency and predictability. Negotiations with planning authorities can start at an early stage as there is a common framework given by BREEAM Communities. Interregional workflow will also be facilitated by this common ground. A very important aspect is that certification is undertaken at the detailed planning application stage, so that it will not depend on the lengthy urban procedures and execution periods. Developers can benefit then at a very early stage, from the international projection of BREEAM, and in case of outstanding performance the project can become a case study in the BREEAM network.

\subsubsection{Benefits for planning authorities}

BREEAM Communities will help Spanish local authorities to turn planning decisions around faster and more confidently as the information provided will be unbiased, thorough and clear. Developers that meet their sustainability commitments can be easily recognized and BREEAM criteria can be tailored to respond to the specific local agenda. It is a valid support to address specific fields where smaller local administrations can lack expertise, such as transport or employment. It is a base for comparison with other local authorities' sustainability performance; this will help in communicating the result of policies to electorate, business and government. 


\subsubsection{Benefits for end users and the community}

Although BREEAM does not certify a community but the planning application (masterplan and documents) it does encourage a series of issues to be thoroughly considered during the design process to improve the environmental quality of the final result. Consequently, the inhabitants of that community will benefit from a quality assurance; by knowing how the masterplan scored against BREEAM standards, they can have a certainty about their prospective living environment before taking a decision.

\subsubsection{Synergies and indirect benefits}

BREEAM is a consolidated tool in the UK, it has more than twenty years of experience and more than 200,000 buildings have been certified worldwide. United Kingdom has traditionally pioneered scientific environmental research and the context was favourable for this type of tool to flourish. There is a high degree of specialization and the role of every professional field is clearly assumed. In Spain much of the work is yet to be done, and for that reason BREEAM Communities is an effective catalyser to activate the demand for specialized research and professional specialization. It opens new fields in the labour market; independent professionals can become BREEAM assessors and offer that new service to their customers. BREEAM Communities encourages a multidisciplinary approach to the urban project as some credit requirements include the involvement of qualified professionals in the fields of ecology, energy or landscape. The implementation of BREEAM Communities will also indirectly promote the development of environmental research and computer tools, as they will find a new outlet in this comprehensive approach. Overall, the global community will benefit from environmental awareness in urban planning and subsequently from better living environments.

\subsection{The adaptation process}

The adaptation of BREEAM Communities has started on last July with the final agreement between BRE Global and the ITG. The first stage in the process is devoted to compile relevant legislation to elaborate an adapted compliant assessment methodology. This is a major task that includes a first approach to the specific framework of Spanish regions. A second stage will consist on extensive consultation with experts in different fields that will be organized in technical groups of discussion. These technical teams will agree and validate the every environmental issue that is included in the different categories. An advisory board will ensure the global coherency and the coverage of all the relevant issues and BRE Global will subscribe the final validation. Finally, the BREEAM Communities will be tested on pilot projects before it is released to the market.

\section{Conclusions}

This essay has explained the relevancy and the scope of the implementation of BREEAM Communities to Spain. It started by defining what a Sustainable 
Community should be and how the current legislation is not enough to provide a favourable scenario. Encouragement of the private sector towards the improvement of the environmental quality of urban developments would greatly decrease the impact of urban growth. Unlike regular EIA, BREEAM Communities allows developers to attain an added value for their product which will spread a higher environmental concern. BREEAM Communities will allow demonstrating the sustainability of a masterplan to local authorities and marketplace; it will also activate environmental industry and specialized professional sectors. ITG is leading this adaptation process that is due to be released by 2011 .

\section{References}

[1] Morris, P. \& Therivel, R. Methods of Environmental Impact Assessment. Spon Press, 2001.

[2] Bell, S. \& McGilliray, D. Environmental Law. Oxford Press University. p.31, 2006

[3] Communities and Local Government .Communities and neighbourhoods. Definition of a sustainable community. Archived online in www.communities.gov.uk/archived/generalcontent/communities/whatis

[4] The Royal Town Planning Institute (RTPI) PPS 13 Environmental Impact Assessment. RTPI, 1995

[5] Ministerio de Medio Ambiente. Real Decreto Legislativo 1/2008 Ley de Evaluación de Impacto Ambiental de proyectos. BOE n²3 26th January 2008. pp4986-5000

[6] Cotter, E. Halewood, J. and Williams, C. Delivering Sustainable Development in the Built Environment. BRE IP 4/09, 2009

[7] Building Research Establishment (BRE) BREEAM Communities. Technical Guidance Manual. BRE Global, 2009 